\title{
SEARCHING FOR THE SECRETS OF NATURE
}




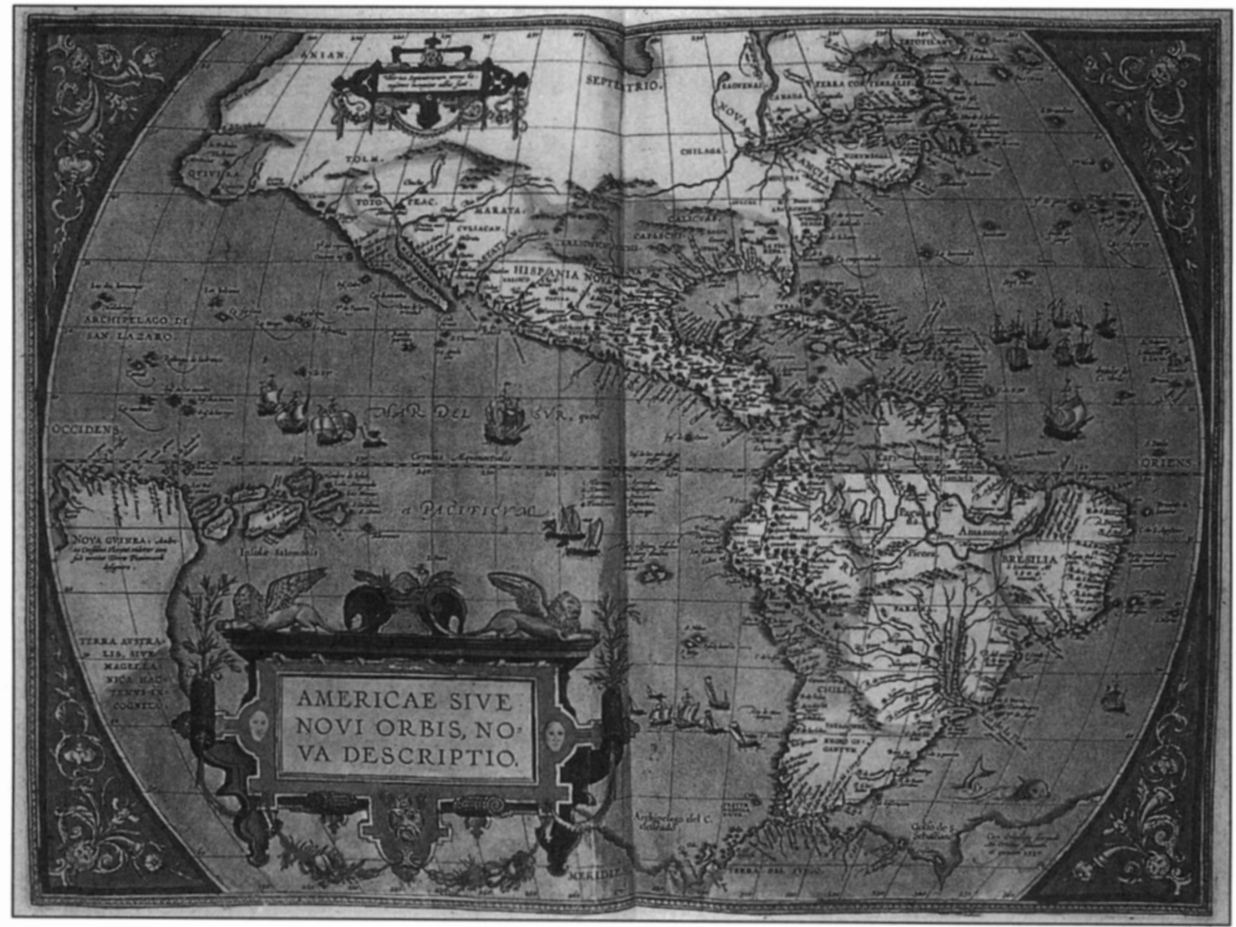

Map of the Americas, drawn in 1587, from Abraham Ortelius, Theatre of the Whole World, first English edition, edited and published by John Norton (London, 1606). Courtesy of the British Library. 


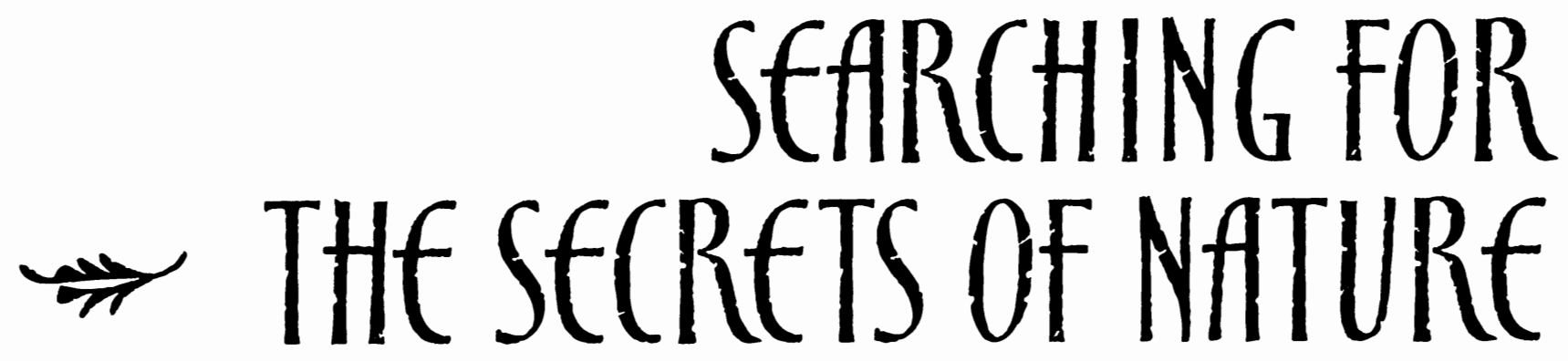

THE LIFE ANDD WORKS

OF DR. FRANCISCO HERNÁNDEZ

S I M O N VA R E Y

R A F A E L C H A B R Á N

D O R A B. W E I N E R

E D I T O R S

S T A N F OR D U N I VERS I T Y PRESS

Stanford, California 
Stanford University Press

Stanford, California

C 2000 by the Board of Trustees of the

Leland Stanford Junior University

Printed in the United States of America

Library of Congress Cataloging-in-Publication Data

Searching for the secrets of nature : the life and works of Dr. Francisco Hernández I edited by Simon Varey, Rafael Chabrán, and Dora B. Weiner.

p. $\mathrm{cm}$.

Includes bibliographical references and index.

ISBN 0-8047-3964-1 (cloth : alk. paper)

1. Hernández, Francisco, 1517-1587. 2. Natural history-Mexico. 3. Materia

medica-Mexico. I. Varey, Simon, 1951- II. Chabrán, Rafael. III. Weiner, Dora B.

QH31.H37 S42 2000

508.72-dc21

00-026518

Original printing 2000

Last figure indicates the year of this printing:

$\begin{array}{lllllllll}08 & 07 & 06 & 05 & 04 & 03 & 02 & 01 & 00\end{array}$

Typeset by Princeton Editorial Associates, Inc., Scottsdale, Arizona, in 9.75/16 Berkeley Old Style Medium. 